\title{
Modelling the snow cover in a complex Alpine topography
}

\author{
Charles Fierz, ${ }^{1}$ Christian Plüss, ${ }^{2}$ Eric Martin ${ }^{3}$ \\ ${ }^{1}$ Swiss Federal Institute for Snow and Avalanche Research, CH-7260 Davos Dorf, Switzerland \\ ${ }^{2}$ Institute of Geography, Swiss Federal Institute of Technology, CH-8057 Zürich, Switzerland \\ ${ }^{3}$ Centre d'Études de la Neige, Centre National de Recherches Météorologiques, Météo-France, 1441 rue de la Piscine, \\ 38406 Saint-Martin-d'Hères Cedex, France
}

\begin{abstract}
The areal distribution of snow cover and the variability of its characteristics were investigated at various locations in the eastern Swiss Alps. An areal energybalance (AEB) model was used to calculate the predominant energy fluxes at the snowatmosphere interface based on automatic meteorological measurements as input. By coupling the AEB model with a one-dimensional, physically based mass and energybalance model of the snow pack, temperature distribution as well as energy and mass flow in the snowpack were simulated at three different locations in the topographically complex environment at Weissfluhjoch-Davos, $2540 \mathrm{~m}$ a.s.l. On a horizontal test site, calculated energy fluxes and characteristics of the snow cover are in good agreement with their measured counterparts. On inclined slopes, the temperature distribution is well represented by the coupled models, but the snow depth and density are not yet satisfactorily simulated. This discrepancy may be attributed to inhomogeneous accumulation and deposition of snow on the weather and lee sides.
\end{abstract}

\section{INTRODUCTION}

The areal distribution of snow cover and the variability of its characteristics are important inputs in climate and hydrological models. In a complex Alpine topography, the extent, depth and density of the snow cover are highly variable (Elder and others, 1991). Therefore, the inclusion of these data in climate and hydrological models is difficult, and very often models are used that need to be locally calibrated (Kirnbauer and others, 1994). Using the coupled models SAFRAN-Crocus, Martin and others (1994) showed the potential of physically based snow-cover models to reproduce and simulate a snow climatology for large Alpine regions without the need for local calibrations. Still, SAFRAN (Système d'Analyse Fournissant des Renseignements Atmosphériques à la Neige) is a sophisticated meteorological model, requiring inputs from other meteorological models (Durand and others, 1993). It calculates the input variables for snow-cover simulations in a model topography over quite large areas (about $1000 \mathrm{~km}^{2}$ ).

For investigations of the snow cover in real topography, however, the influences of the surrounding terrain (e.g. shading effects, reflections and emission from the terrain) have to be included on a smaller scale. For this purpose an areal energy-balance (AEB) model has been developed (Plüss, 1996), based on automatic meteorological measurements as input. The model parameterizes the predominant energy fluxes at the snow-atmosphere interface in a digitized terrain model (grid size $25 \times 25 \mathrm{~m}^{2}$; total area $4 \times 4 \mathrm{~km}^{2}$ ), including parameterizations of the diffuse and direct sky irradiance and of the irradiance from the surrounding topography in both the shortwave and longwave range. The AEB model was successfully tested during the 1995 ablation period of the snow cover in the eastern Swiss Alps (Plüss, 1996).
The purpose of this work was to drive a physically based snow-cover model (Crocus) with the hourly output of the AEB model in order to simulate the temperature and mass evolution of the snowpack on inclined terrain, and to assess its potential for use in climate and hydrological studies. A qualitative verification of the models' performance was done during the pre-melt season by taking several temperature and snow profiles on south- and north-facing slopes, and by comparing simulated and measured energy fluxes on a well-equipped study site.

\section{METHODS}

The evolution of snow cover was simulated at three locations near the Swiss Federal Institute for Snow and Avalanche Research at Weissfluhjoch/Davos: the flat study site of the institute (at $2540 \mathrm{~m}$ a.s.l.) and the adjacent south- and north-facing slopes of the Totalphorn $(2480 \mathrm{~m}$ a.s.l., inclination $36^{\circ}$ and $2470 \mathrm{~m}$ a.s.l., inclination $38^{\circ}$, respectively) (Fig. 1). The simulation of the snowpack on the flat study site allows detailed and continuous checks of model outputs. The simulation period extends from 1 March $19960100 \mathrm{~h}$ UTC to 2 May $19960000 \mathrm{~h}$ UTC.

The hourly input to the AEB model was taken from the automatic weather station located at Weissfluhjoch, $2693 \mathrm{~m}$ a.s.l. (data taken included air temperature, wind speed, relative humidity and global radiation) and from the mean of three daily observations at Weissfluhjoch (cloudiness). The 24 hour water equivalent of fresh snow measured on the study site was distributed over the day according to the precipitation sequence recorded with a rain gauge. The main precipitations during the period studied were accompanied by moderate winds blowing mainly from northwest to north. The period 20-24 April 


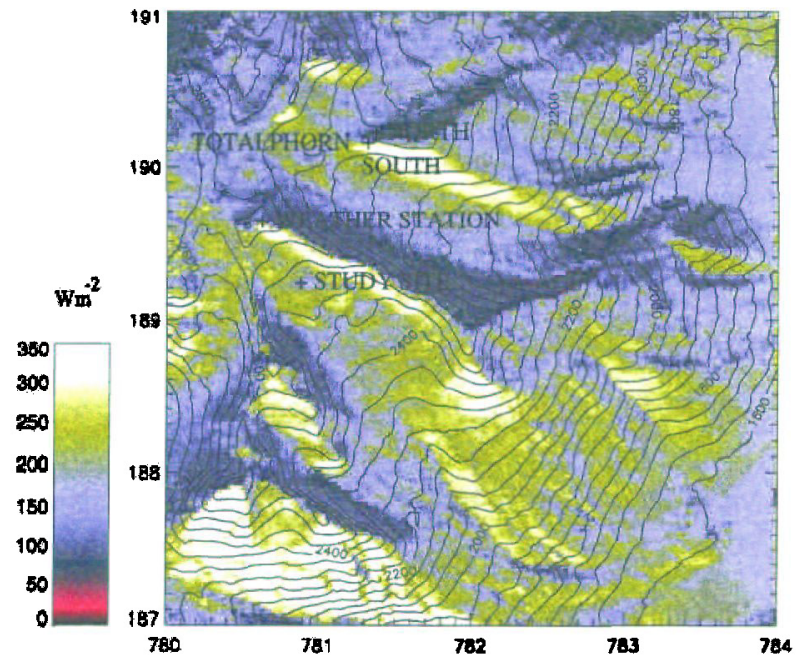

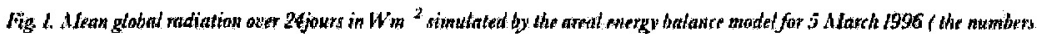

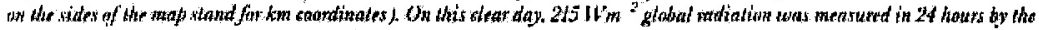

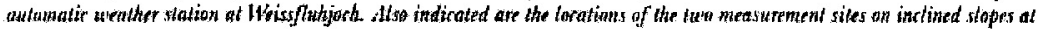

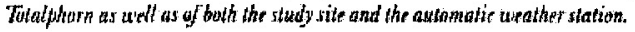

was characterized by air lemperatures near $00^{\circ} \mathrm{C}$ and suslained gusty soutl 1 winds.

The areal distrilut ien of the predeminatat energy fluxes ai the snow surface was modelled by the AEB model, using hourly antomatic weather station data as inpul. The mean atmospheric transmission for clear-sky situations is calculated from the transmissivities of thr most impartant aeinsols and mulecules in the ulmowphere (see Dozier, 1980), but meglecring the wavelength dependetiry. The inlluenre of eloud crwier was calculated from the ralio of measured global radiation to the top-of-atmosphere radiation. On inclined surfaces, the eflocts of the surrounding terrain are included for diffusc and direct radiation. For the calculation of longwave-radiation balance. the effects of cloud ower and the radiation frumt the surrounding topography are taken into account. The turbulent fluxes are calculated assuming an arreal constant drag confficient for each tiniestep. Wind ypeed was calculated from a meen gradient estimaned from previnusly recorded wind speeds at Weissliuhjoch

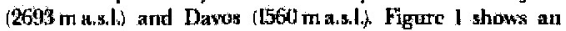
AEB model ciutput for daily mean global radiation.

The huortly output of the AEB model (air temperature, wind sperd, relative humidity, incoming dired and diffuse shortwave radiation and inconing lomgwave radiation) as well as cloudiness and study site precipitation were ufed to run Crocus. It is a one-dimensional (1-D). phyeically hased mass and energy-balance model of the mowpack Brun and others, 14923, which simulates the intenal evolution of the snow cover including the most important physical precesses (temperature distribution, settling metanorphosis, simplified percolation, etc). According to prior studies of snow accumulation in the same area (Fohn, 1980). precipitations inferred from the atudy aite werc redueed by $25 \%$ on the windy weather side I north, erosion) whereas they were increased by $25 \%$ for the lee side (snuth, depnsition).
To check un the consistency of the model outpus, Grocus was also rut will meleorological data measured antomatcally on the study site. Locoming shortwawe and longwave ratiation are mezsured separately, and may be directly used by Crorus. Cloutiness as well as separation into dinert and diffuse incoming thortwave radiation were extimated using the parameterizations included in the model.

th initialize Crocus, as well as Io verify its outputs, snow proliles were taken every if? 14 diys over the test period on all thee sites sis profiles eath were taken around $0800 \mathrm{~h}$ LTC on the south-facing slope and around $1300 \mathrm{~h}$ ("TC. either the day before or the same day on the north slope. Profiles ori the study sitc are usually taken aroutd $0900 \mathrm{~h}$ LTC. Special hare was given to the measurement of both temperature and dirtsity profiles. Stratigraphy was recotded, but will not be presentut in this paper.

\section{RESULTS}

Figure 2a showh olse automarically recerded snow depth an the sludy site as eompared to the simulation driven by the output of the AER model. The simulated snow dopth is calculated from the rccordrd water equivalem of precipications, taking account of both air temperature and wind.

The energy balance at the snow-atmosphere interface is reftected in the surface temperature $T_{n}$ as long as $T_{x}<0^{\circ} \mathrm{C}$ (Kondo and Yamazaki, 1990). Thus as a first check. the surface temperature calculated by the sinow-cover model may be compared to rarasured values of $T_{\mathrm{s}}$. Indeed, thanks tn a careful ralibratinn or inlrared thermume ters (Wilennanu, 1996), the snow-surface temperature $T_{*}$ may uectrately be smeasured on the study site at Weissfluhy oeh. Figure 2b shows the comparison of the measured surfare Iemperature to the simulated one using inpur data from the AEB model. 


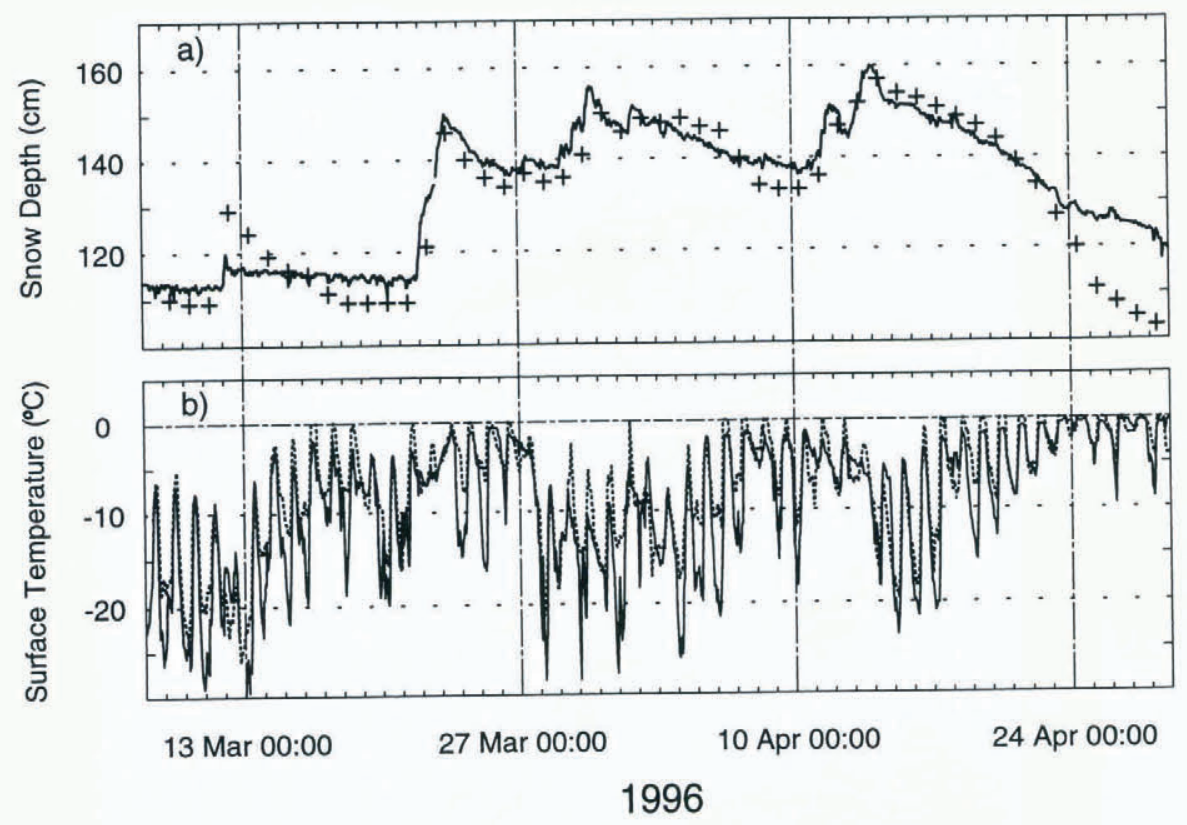

Fig. 2. (a) Snow depth and (b) surface temperature on the study site at Weissfluhjoch. Solid line is measured; crosses are simulated with $A E B$ model data as input.

For all sites, measured profiles taken from snow pits are compared to simulated temperature profiles in Figure 3. The first profile on each site, including stratigraphy, was used to initialize Crocus. Also shown for the study site are the results of the simulation with study site data as well as temperature profiles recorded automatically with evenly spaced $(20 \mathrm{~cm})$ fixed sensors. Furthermore, both measured and simulated values of the water equivalent and the mean density of the snow cover are given at the top of the corresponding profiles.

\section{DISGUSSION}

Since the AEB model showed promising results for modelling the ablation of the snow cover in a complex topography (Plüss, 1996), the purpose of this study was to assess the ability of the coupled AEB - Crocus models to simulate qualitatively the internal evolution of the snow cover in a complex Alpine topography. However, running the AEB-model with hourly input and output data may lead to difficulties with respect to the simulation of turbulent fluxes. Due to the high variability of wind speed in time and space, the bulk parameterizations for hourly means of these fluxes may be biased by a considerable error (Plüss and Mazzoni, 1994). For daily means, however, these errors are small with respect to the magnitude of the radiative fluxes. Thus the focus has been set on long-term properties such as water equivalent and the mean density of the snow cover, as well as the time evolution of the temperature gradient in the lower part of the snowpack.

The results for the study site are satisfactory. Even though the difference between simulated and measured temperature gradients on the lower part of the snowpack may be up to the order of $25 \%$, the time evolution is correctly modelled. There is a problem, however, regarding the overnight cooling of the surface (Fig. 2b). Indeed, the model tends to overestimate the surface temperature $T_{\mathrm{s}}$. Least squares fits of the modelled surface temperatures vs the measured one yielded $\mathrm{R}^{2}$ terms of 0.807 (slope $=0.73$ ) for the AEB-driven run and 0.944 (slope $=0.91$ ) with study site data as input. This effect, however important for processes and temperature gradients near the surface, will not affect the long-term internal evolution of the lower part of the snow pack by much.

In terms of mass balance, measured and modelled water equivalents and mean densities agree within $13 \%$. This scatter may be due to both small-scale inhomogeneities or the accumulation on the study site and measurement errors. Noteworthy is the strong simulated settling of snow cover during the warm period from 20-24 April (Fig. 2), probably as a result of an anticipatory simulated wet-snow metamorphism of the lowest layers of the snow pack.

Larger discrepancies, however, arise for the snow-cover simulation on sloped terrain, especially regarding mass balance. Problems may be due either to overdensification (first four profiles on Totalphorn south) as described above for the study site or to large inhomogeneities in the accumulation that could not be correctly modelled due to a lack of accurate wind field data. Moreover, the collection of field data on slopes is problematic in itself and the exact location of the snow pits may vary by up to $20 \mathrm{~m}$, or even more on the north-facing slope. The latter may be the main reason for the differences arising between simulated and measured profiles at Totalphorn north on 3 April. Substantial improvements are needed for both mass balance and settling. Whereas settling may be improved through detailed investigations of measurements on the study site, the areal variability of snow depth on slopes due to wind effects and local topography will remain a problem until better snow-drift models are available. Furthermore, water percolation on inclined terrain cannot be represented well enough with a l-D model, influencing also the computation of mass balance.

Nevertheless, the obvious ability of the coupled models to simulate quite correctly the evolution of temperature gradients of the lower part of the snowpack on both south- and north-facing slopes is encouraging for future applications. Indeed, using "representative" snow depths for given aspects and altitudes, these models will be valuable for climatic and hydrological studies since there is no need for local calibra- 
a) Totalphorn South at 08 UTC

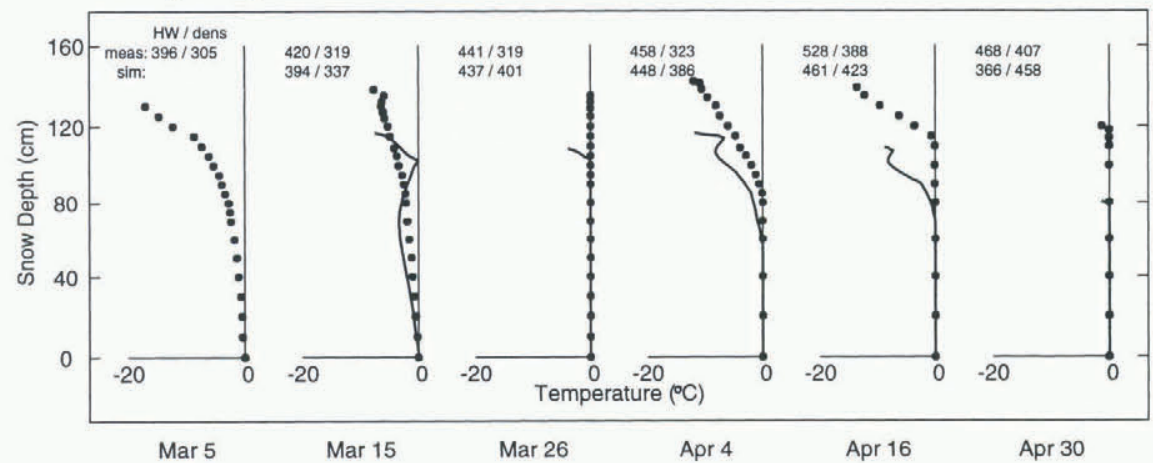

b) Totalphorn North at 13 UTC

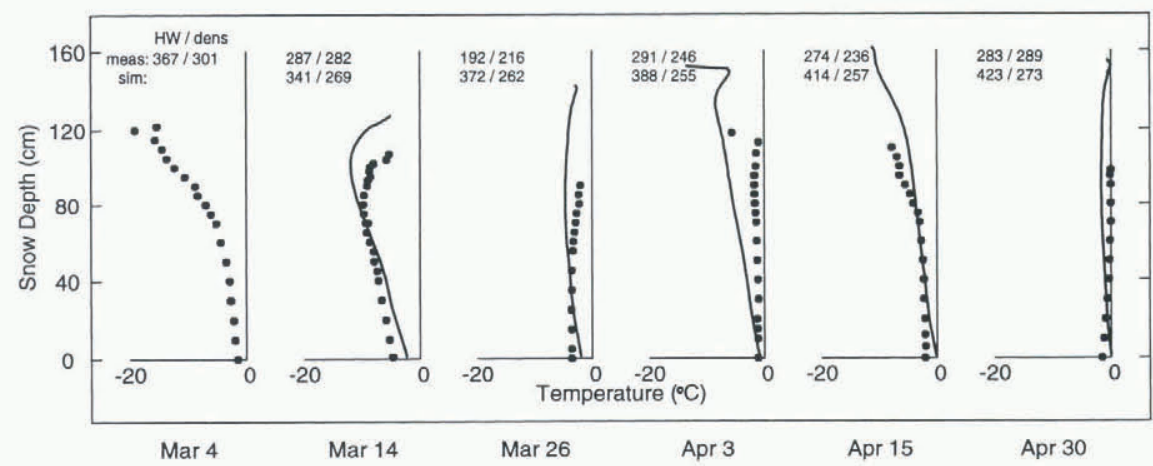

c) Study Site at 09 UTC

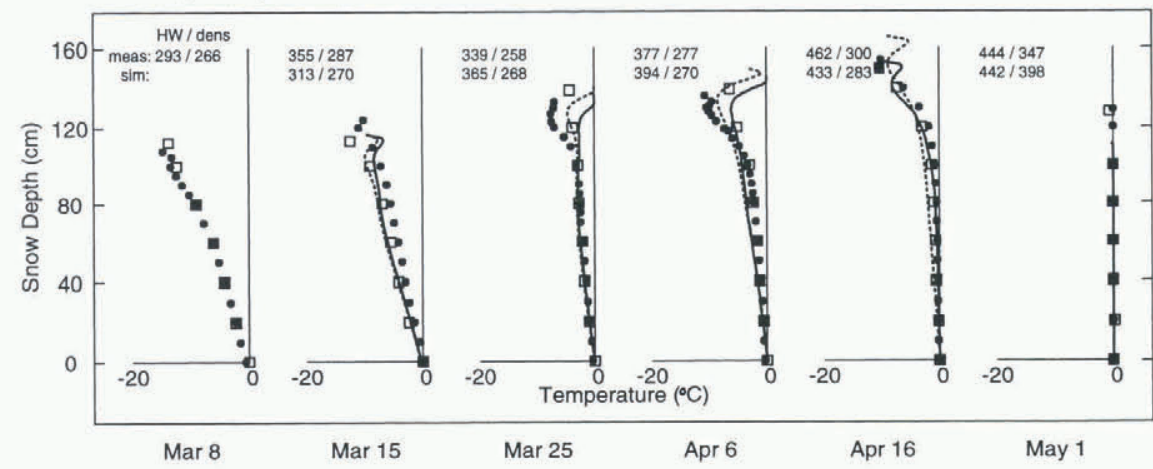

Fig. 3. Temperature profiles on (a) Totalphorn south, (b) Totalphorn north and (c) the study site. The first profile on each site was used to initialise Crocus. Filled circles are measured profiles (snow pits); solid lines are simulations with AEB model data; hatched lines are simulations for the study site with study-site data; squares are automatically recorded profiles on the study site. Measured (snow pits) and simulated values of both the water equivalent $\mathrm{HW}$ in mm $\mathrm{H}_{2} \mathrm{O}$ and the mean density dens in $\mathrm{kg} \mathrm{m}^{-3}$ of the snow cover are given on top of the corresponding profiles.

tions. On the other hand, this short study underlines once more the need for accurate field data for verification and, at this stage, cross-checks with simulations on flat and representative sites are essential to gain confidence in the performance of the models.

\section{CONCLUSIONS}

Satisfactory modelling of both the temperature and mass evolution of a snowpack in a complex Alpine topography over a 2 month period with models that do not require to be locally calibrated has been demonstrated. The importance of accurate field data to verify model outputs has been underlined. A better knowledge of the wind field, and hence of the accumulation and turbulent fluxes, as well as of physical processes like settling and water percolation, should lead to improved mass and energy balances. Such models may then be of value for climatic and hydrological studies in Alpine environments. Finally, the possibility of using energy-balance models at the snow-atmosphere interface to produce input data for physically based snow-cover models will also be of value for regional avalanche forecasting.

\section{ACKNOWLEDGEMENTS}

We would like to thank P. M. B. Föhn for having initiated and supported this study. We are also indebted to A. Awlad, K. Mellini, M. Phillips, E. Beck, D. Bühlmann, C. Camponovo, P. Gauer, R. Meister, C. Oberschmied, M. Schär and P. Weilenmann who helped to collect the field data.

\section{REFERENCES}

Brun, E., P. David, M. Sudul and G. Brunot. 1992. A numerical model to simulate snow-cover stratigraphy for operational avalanche forecasting. j. Glaciol., 38 (128), 13-22.

Dozier, J. 1980. A clear-sky spectral solar radiation model for snow-covered mountainous terrain. Water Resour. Res., 16 4), 709-718. 
Durand, Y., E. Brun, L. Merindol, G. Guyomarc'h, B. Lesaffre and E. Martin. 1993. A meteorological estimation of relevant parameters for snow models. Ann. Glaciol., 18, 65-71.

Elder, K., J. Dozier and J. Michaelsen. 1991. Snow accumulation and distribution in an alpine watershed. Water Resour. Res., 27 (7), 1541-1552.

Föhn, P. M. B. 1980. Snow transport over mountain crests. J. Glaciol., 26 (94), $469-480$.

Kirnbauer, R., G. Blöschl and D. Gutknecht. 1994. Entering the era of distributed snow models. Nord. Hydrol., 25 (1-2), 1-24.

Kondo, J. and T. Yamazaki. 1990. A prediction model for snowmelt, snow surface temperature and freezing depth using a heat balance method J. Appl. Meteorol., 29 (5), 375-384.

Martin, E., E. Brun and Y. Durand. 1994. Sensitivity of the French Alps snow cover to the variation of climatic variables. Annales Geophysicae, $12(5), 469-477$.

Plüss, C. 1996. The energy balance over Alpine snowcover - point measurements and areal distribution. (Ph.D. thesis, ETH, Zürich. Geographisches Institut.)

Plüss, C. and R. Mazzoni. 1994. Role of turbulent heat fluxes in the energy balance of high Alpine snow cover. Nord. Hydrol., 25 (1-2), 25-38. 